TITLE:

\title{
Eicosapentaenoic acid facilitates the folding of an outer membrane protein of the psychrotrophic bacterium, Shewanella livingstonensis Ac10.
}

\section{$\operatorname{AUTHOR}(\mathrm{S})$ :}

Dai, Xian-Zhu; Kawamoto, Jun; Sato, Satoshi B; Esaki, Nobuyoshi; Kurihara, Tatsuo

\section{CITATION:}

Dai, Xian-Zhu ... [et al]. Eicosapentaenoic acid facilitates the folding of an outer membrane protein of the psychrotrophic bacterium, Shewanella livingstonensis Ac10.. Biochemical and biophysical research communications 2012, 425(2): 363-367

\section{ISSUE DATE:}

2012-08-24

\section{URL:}

http://hdl.handle.net/2433/159938

\section{RIGHT:}

(C) 2012 Elsevier Inc.; This is not the published version. Please cite only the published version.; この論文は出版社版でありません。引用の際に は出版社版をご確認ご利用ください。 
Eicosapentaenoic Acid Facilitates the Folding of an Outer Membrane Protein of the Psychrotrophic Bacterium, Shewanella livingstonensis Ac10

Xian-Zhu DAI ${ }^{\mathrm{a}}$, Jun KAWAMOTO ${ }^{\mathrm{a}}$, Satoshi B. SATO ${ }^{\mathrm{b}}$, Nobuyoshi ESAKI ${ }^{\mathrm{a} \ddagger}$, Tatsuo KURIHARA $^{\mathrm{a}^{*}}$

${ }^{a}$ Institute for Chemical Research, Kyoto University, Uji, Kyoto 611-0011, Japan

${ }^{\mathrm{b}}$ Research Center for Low Temperature and Materials Sciences, Kyoto University, Kyoto 606-8501, Japan

*Corresponding author. Mailing address: Institute for Chemical Research, Kyoto University, Uji, Kyoto 611-0011, Japan. Phone: +81-774-38-4710 Fax: +81-774-38-3248 E-mail: kurihara@scl.kyoto-u.ac.jp

$\ddagger$ Recipient of 2009 Humboldt Research Award

Key words: eicosapentaenoic acid, phospholipid, membrane protein, protein folding, cold-adaptation mechanism, bacteria 


\section{Abstract}

Polyunsaturated fatty acids, such as eicosapentaenoic acid (EPA), are found in various cold-adapted microorganisms. We previously demonstrated that EPA-containing phospholipids (EPA-PLs) synthesized by the psychrotrophic bacterium Shewanella livingstonensis Ac10 support cell division, membrane biogenesis, and the production of membrane proteins at low temperatures. In this article, we demonstrate the effects of EPA-PLs on the folding and conformational transition of Omp74, a major outer membrane cold-inducible protein in this bacterium. Omp74 from an EPA-less mutant migrated differently from that of the parent strain on SDS-polyacrylamide gel, suggesting that EPA-PLs affect the conformation of Omp74 in vivo. To examine the effects of EPA-PLs on Omp74 protein folding, in vitro refolding of recombinant Omp74 was carried out with liposomes composed of 1,2-dipalmitoleoyl-sn-glycero-3-phosphoglycerol and 1,2-dipalmitoleoyl-sn-glycero-3-phosphoethanolamine (1:1 molar ratio) with or without EPA-PLs as guest lipids. SDS-PAGE analysis of liposome-reconstituted Omp74 revealed more rapid folding in the presence of EPA-PLs. CD spectroscopy of Omp74 folding kinetics at $4{ }^{\circ} \mathrm{C}$ showed that EPA-PLs accelerated $\beta$-sheet formation. These results suggest that EPA-PLs act as chemical chaperones, accelerating membrane insertion and secondary structure formation of Omp74 at low temperatures. 


\section{Introduction}

Long-chain polyunsaturated fatty acids (LPUFAs) such as eicosapentaenoic acid (EPA,

20:5n3) and docosahexaenoic acid (DHA, 22:6n3) are found in the cell membranes of various marine bacteria [1]. Many have been isolated from permanently cold environments, such as deep-sea and polar regions. Members of the Shewanella genus that produce varying amounts of EPA as an acyl chain of membrane phospholipids exhibit a good correlation between cold-adaptation and EPA production [2].

EPA functions as an antioxidative component at low temperatures and influences the hydrophobicity of the bacterial cell membrane, thus affecting the entry of hydrophilic and hydrophobic compounds [3]. In addition to these functions, EPA in bacteria growing at low temperatures is assumed to improve membrane fluidity and decrease phase transition temperature of phospholipid membranes due to the low packing order of its poly cis unsaturated acyl chain. Appropriate membrane physical properties are essential for many biological processes, such as membrane protein dispersion, protein-protein interaction, and protein-lipid interaction within the lipid bilayers [4]. LPUFAs modulate a variety of biological processes and alter the functions of several membrane proteins such as sarcolemmal ion channels and rhodopsin $[5,6]$. However, the molecular mechanisms by which PUFAs interact with these proteins and modulate their function in lipid bilayers remain unclear.

A psychrotrophic bacterium isolated from Antarctic seawater, Shewanella livingstonensis Ac10, produces EPA as the $s n-2$ acyl chain of phospholipids, constituting about $5 \%$ of the total fatty acids in cells grown at $4{ }^{\circ} \mathrm{C}$ and less than $1 \%$ when grown at $18^{\circ} \mathrm{C}$ [7]. EPA plays an important role in cell growth, cell division, and membrane biogenesis of S. livingstonensis Ac10 at low temperatures [7]. EPA deficiency alters the composition of membrane proteins, 
although the small amount of EPA produced in S. livingstonensis Ac10 did not cause a detectable increase in bulk membrane fluidity [7]. These results suggest that, rather than maintaining membrane fluidity, EPA more specifically influences the behaviors of membrane proteins in S. livingstonensis Ac10.

We found in the present study that in an EPA-less mutant, one of the major outer membrane cold-inducible proteins, Omp74 (GenBank ID: BAF64763), forms a conformation different from that in the parent strain at $4^{\circ} \mathrm{C}$, suggesting that EPA-containing phospholipids (EPA-PLs) contribute to the folding of this protein at low temperatures. We constructed an in vitro Omp74 reconstitution system by using chemically synthesized phospholipids and found a novel function of EPA-PLs, facilitating folding of this membrane protein as chemical chaperones at low temperatures. 


\section{Materials and Methods}

Strains, plasmid, and growth conditions

The bacterial strains and plasmid used in this study are summarized in Table S1. A

rifampin-resistant mutant of $S$. livingstonensis Ac10 (parent strain) and the EPA-less mutant ( $\triangle \mathrm{EPA})$ were grown in Luria-Bertani (LB) medium at $4^{\circ} \mathrm{C}$. Seed cultures of the parent strain and $\triangle \mathrm{EPA}$ were grown at $18^{\circ} \mathrm{C}$. When required, antibiotics were added to the medium at the following concentrations: rifampin, $50 \mu \mathrm{g} \mathrm{mL}^{-1}$ and kanamycin, $30 \mu \mathrm{g} \mathrm{mL}^{-1}$.

\section{Preparation of purified recombinant Omp74}

To obtain recombinant Omp74 as inclusion bodies in Escherichia coli, an omp74-overexpression vector was constructed and recombinant Omp74 was purified as described in Supporting Information.

\section{Western-blot analysis of Omp 74}

The parent strain and EPA-less mutant of S. livingstonensis Ac10 were cultivated at $4{ }^{\circ} \mathrm{C}$ and collected at late-log phase, $\mathrm{OD}_{600}=0.5-1.0$; early-stationary phase, $\mathrm{OD}_{600}=1.0-2.5$; and late-stationary phase, $\mathrm{OD}_{600}=2.5-4.0$. All samples were normalized by $\mathrm{OD}_{600}$. Cells were disrupted by sonication. Crude membrane proteins were collected by centrifugation at 30,000 $\mathrm{x} g$ for $60 \mathrm{~min}$ and resuspended in 2\% (w/v) $N$-lauroylsarcosine sodium salt (Sigma, St. Louis, MO, USA). Samples were not heated before loading onto SDS-PAGE if not noted. Omp74 was detected with 80,000-fold diluted anti-Omp74 serum (Supporting Information) and an ECL plus kit ${ }^{\mathrm{TM}}$ (Amersham Pharmacia Biotech, Piscataway, NJ, USA) according to the standard 
protocol.

\section{EPA-PL synthesis}

To mimic the cell membrane of S. livingstonensis Ac10, phospholipids containing palmitoleic acid and EPA were synthesized as described in Supporting Information [8]. All other phospholipids were purchased from Avanti Polar Lipids (Alabaster, AL, USA).

\section{Liposome preparation}

Liposomes were prepared as described previously, with slight modification [9]. Four micromoles of phospholipids dissolved in chloroform were dried to a thin film in glass tubes with nitrogen gas stream, and then placed under vacuum for more than 30 min to remove residual chloroform. The dried lipid films were hydrated in $400 \mu \mathrm{L}$ of TED buffer (pH 8.0) containing $10 \mathrm{mM}$ Tris-HCl, $1.5 \mathrm{mM}$ EDTA, and $0.5 \mathrm{mM}$ 1,4-dithio-D,L-threitol, agitated by vortexing for at least $30 \mathrm{~min}$, and sonicated in a bath sonicator until the solutions became translucent. The liposome solutions were equilibrated at $4^{\circ} \mathrm{C}$ for 3 days before use. At all steps of the liposome preparation, nitrogen gas was added to the container to prevent oxidation of unsaturated acyl chains. The sizes of the liposomes used for folding kinetics studies were analyzed with a DynaPro 801 dynamic light scattering instrument (Protein Solutions, Chicago, IL, USA). The average diameters of liposomes made from 1,2-dipalmitoleoyl-sn-glycero-3-phosphoethanolamine (DPPE) and 1,2-dipalmitoleoyl-sn-glycero-3-phosphoglycerol (DPPG) (1:1 molar ratio) and those containing 1-palmitoleoyl-2-eicosapentaenoyl-sn-glycero-3-phosphoethanolamine (PEPE) and 
1-palmitoleoyl-2-eicosapentaenoyl-sn-glycero-3-phosphoglycerol (PEPG) (2.5 mol\% each) were $50-55 \mathrm{~nm}$.

\section{In vitro reconstitution of $\mathrm{Omp} 74$}

Purified inclusion bodies of Omp74 were dissolved with $8 \mathrm{M}$ urea in TED buffer (pH 8.0) and centrifuged for $30 \mathrm{~min}$ to remove insoluble materials. Protein concentration was measured with Bio-Rad Protein Assay Kit (Bio-Rad, Hercules, CA, USA) and the final concentration was adjusted to $0.5 \mathrm{mM}$. In vitro reconstitution was performed by rapidly diluting recombinant Omp74 unfolded in $8 \mathrm{M}$ urea by 50 -fold in liposome solutions to a final lipid concentration of 5 $\mathrm{mM}$ and $1.25 \mathrm{mM}$ for SDS-PAGE and circular dichroism (CD) spectroscopy, respectively, and incubated at the temperatures indicated in the Results. Folding was stopped by the addition of SDS sample buffer to a final concentration of $2 \%$ SDS, $2 \mathrm{mM} \beta$-mercaptoethanol, $4 \%$ glycerol, 0.2 M Tris- $\mathrm{HCl}$, and $0.1 \%$ bromophenol blue (Takara Bio, Tokyo, Japan). Samples were stored at $-30^{\circ} \mathrm{C}$ as necessary. Omp 74 band intensity was quantified by densitometry with Image $\mathrm{J}$ software version 1.14. All values were normalized to the band intensities of the protein marker. Folding efficiency was calculated by dividing the intensity of the folded protein band by the total intensity of the unfolded and folded protein bands.

\section{CD spectroscopy}

CD spectra were measured using a JASCO J-820-L Circular Dichroism Spectropolarimeter (Jasco Inc., Tokyo, Japan). The far-UV spectrum was recorded in the spectral range 210-250 $\mathrm{nm}$ and averaged over 4 scans at $18^{\circ} \mathrm{C}$, using a $1 \mathrm{~mm}$ path-length cell. Liposomes in TED buffer 
( $\mathrm{pH}$ 8.0) were used to obtain a baseline, and the background was subtracted automatically during scanning. For folding kinetics at $4{ }^{\circ} \mathrm{C}$, the signal at $215 \mathrm{~nm}$ was monitored every $0.5 \mathrm{~s}$ for $15 \mathrm{~min}$. To analyze the folding kinetics of Omp74, a moving average was calculated from the values of every 10 scans. 


\section{Results}

\section{EPA deficiency affected Omp74 folding in vivo}

Crude membrane proteins were extracted from early stationary phase S. livingstonensis Ac10 and EPA-less mutant ( $\triangle \mathrm{EPA}$ ) cells grown at $4{ }^{\circ} \mathrm{C}$ and analyzed by western blotting with an anti-Omp74 serum. Figure 1 shows Omp74 in the parent and $\Delta$ EPA strains. When the crude membrane proteins were not boiled, 2 main bands of about 34 and $32 \mathrm{kDa}$ were observed in the parent strain (F1 and F2, respectively). Bands of differing mobility presumably represent Omp74 in different tertiary structures, but not nonspecific cross-reacted or truncated Omp74, because boiled samples gave a single main band of $39 \mathrm{kDa}$ corresponding to the theoretical molecular mass (Fig. 1). These results indicate that the defect of EPA affects the folding of Omp74 in vivo.

\section{EPA-PLs facilitate folding of Omp74 in vitro}

In order to examine the involvement of EPA-PLs in the folding of Omp74, we carried out in vitro reconstitution of Omp74 in the presence of $n$-octyl- $\beta$-D-glucopyranoside (OG) and chemically synthesized phospholipids. The phospholipids containing palmitoleic acid at $s n-1$ and EPA at sn-2 were used as the characteristic molecular species in S. livingstonensis Ac10 grown at $4{ }^{\circ} \mathrm{C}$. Omp74 in the $\mathrm{F} 1$ form was found when liposomes and $\mathrm{OG}$ were used (Fig. S1), and the F1 band disappeared after heat treatment. This demonstrates that Omp74 was folded into the F1 form, which was found in the living cells, by the presence of liposomes and micelles. The F2 form of Omp74 was, however, not induced under the present experimental conditions, probably due to the lack of a chaperone molecule involved in the in vivo formation of the F2 
form.

To investigate the effects of EPA-PLs on Omp74 folding into the F1 form, the kinetics of in vitro folding was analyzed by SDS-PAGE. After incubation of unfolded Omp74 with the liposomes composed of DPPG/DPPE with or without EPA-PLs, Omp74 was applied to SDS-PAGE. In the presence of liposomes, the F1 form of Omp74 was detected at $20 \mathrm{~min}$ at $18^{\circ} \mathrm{C}$ and $4^{\circ} \mathrm{C}$, and increased over time (Fig. 2 left panels). We determined the folding kinetics by calculating the band intensities of the F1 form and unfolded Omp74 (Fig. 2 right panels), which revealed that Omp74 refolding into the F1 form was facilitated by EPA-PLs. About $65 \%$ and 35\% of Omp74 incubated with EPA-PLs was refolded within $360 \mathrm{~min}$ and 1,020 min at $18^{\circ} \mathrm{C}$ and $4^{\circ} \mathrm{C}$, respectively. Without EPA-PLs, only about $40 \%$ and $20 \%$ of Omp 74 was refolded at $18^{\circ} \mathrm{C}$ and $4^{\circ} \mathrm{C}$, respectively.

\section{及-Sheet formation of Omp74 in EPA-containing liposomes}

Omp74 shares about $44 \%$ amino acid identity with E. coli OmpA (GenBank ID: AF234269) and is predicted to form transmembrane $\beta$-barrel structures. The CD spectrum of Omp74 folded in buffer lacking liposomes showed a negative Cotton effect at $215 \mathrm{~nm}$ [10], revealing that Omp74 adopted a $\beta$-sheet-rich structure in aqueous solution after urea dilution (Fig. 3A). To determine the effects of EPA-PLs on the main-chain conformation of Omp74, we analyzed CD spectra of Omp74 reconstituted in liposomes with or without EPA-PLs and found they were similar to each other after prolonged incubation (Fig. 3A).

The kinetics of $\beta$-sheet formation of Omp 74 at $4^{\circ} \mathrm{C}$ was analyzed by monitoring changes in the CD signal at $215 \mathrm{~nm}$. After dilution into the liposome solutions, there was an initial decrease 
(upward in the graph) in CD signal derived from Omp74 diluted with liposomes with (1.5 min) and without (3 min) EPA-PLs, as indicated by arrowheads in Figure 3B. Then the signal increased (downward in the graph) rapidly. This result indicates that Omp74 rearranged its secondary structures as it folded into the lipid bilayer. In the presence of EPA-PLs, the CD signal at $215 \mathrm{~nm}$ rapidly decreased within $1.5 \mathrm{~min}$ and then increased until $9 \mathrm{~min}$. In the absence of EPA-PLs, the increase in CD signal after 3 min was slower. These results demonstrate that EPA-PLs facilitated the rearrangement and formation of Omp $74 \beta$-sheet structures in lipid bilayers. When Omp74 was diluted in buffer lacking liposomes, the CD signal increased over time, indicating that, in aqueous solution, Omp74 was folded into $\beta$-sheet-rich structures without rearrangement. 


\section{Discussion}

In cold environments, the efficiency of molecular dynamics decreases, influencing enzyme activity and membrane fluidity [11]. To survive such unfavorable conditions, a psychrotrophic bacterium, S. livingstonensis Ac10, developed unique cold-adaptation mechanisms. To characterize the cold-adaptation mechanism of this bacterium, we focused on the physiological function of its cell membrane. S. livingstonensis Ac10 produces EPA as an acyl chain of its membrane phospholipids, PG and PE [7]. It is known that phospholipids containing LPUFAs affect the physicochemical properties of lipid bilayers, such as membrane thickness, permeability, elasticity, and curvature [4]. We found that an EPA-less mutant grown at $4^{\circ} \mathrm{C}$ has defects in cell division, membrane biogenesis, and biosynthesis of several membrane proteins including outer membrane porins, strongly suggesting that EPA-PLs are required for function of various membrane proteins at low temperatures $[7,12]$.

In this study, we focused on an outer membrane protein, Omp74, a cold-inducible protein, to analyze its interaction with EPA-PLs. Omp74 is a predicted outer membrane porin that serves as a membrane passage for hydrophilic compounds and stabilizes the outer membrane structure, as an omp74-disrupted strain exhibited osmotic sensitivity (unpublished data). Western blotting of Omp74 in the EPA-less mutant grown at $4{ }^{\circ} \mathrm{C}$ indicates that Omp74 migrates differently than that of the parent strain (Fig. 1). Since this mobility shift is caused by altered protein folding, EPA might interact with Omp74 and modulate its folding [14,15].

We created an in vitro Omp74 reconstitution system by using chemically synthesized PGs and PEs containing palmitoleic acid, which are major phospholipids in the cell membrane of $S$. livingstonensis Ac10, and EPA-PLs to mimic the physiological membrane. Omp74 
reconstituted with various liposomes and micelles showed a band on SDS-PAGE corresponding to the F1 form observed in vivo (Figs. 1 and S1). However, under this in vitro condition, the F2 form of Omp74 produced in the presence of EPA in vivo was not detected. The formation of the F2 form probably requires a chaperone molecule, in addition to EPA, that was not included in the in vitro reaction mixture. Although the F1 form of Omp74 was produced even in the absence of EPA in vivo (Fig. 1), we found that EPA-PLs significantly affect the production of this form in vitro (Fig. 2). Folding speed to produce the F1 form increased in the presence of EPA-PLs. Thus, EPA-PLs support Omp74 folding in lipid bilayers.

The CD signal (215 nm) derived from Omp74 incubated with liposomes with and without EPA-PLs decreased (upward in the graph) until 1.5 and 3 min, respectively, then increased (downward in the graph) (Fig. 3B). During this period, the secondary structures of denatured Omp74 was supposed to be rearranged on the lipid bilayers surface. The increase in CD signal was likely due to reconstruction of the $\beta$-sheet structures in hydrophobic environments [16]. During refolding of Omp74, EPA-PLs probably facilitate interaction with the membrane surface, insertion into the hydrophobic environment, and reconstruction of the $\beta$-sheet structures in the lipid bilayer. DHA, an analogue of EPA, forms diverse conformations compared to monounsaturated fatty acids, which allows DHA to solvate the rough surface of membrane proteins with lower energetic costs [17]. Solvation by LPUFAs would facilitate folding of membrane proteins at low temperatures.

These results suggest that EPA acts as a chemical chaperone in the hydrophobic lipid core. Although our findings have not revealed the molecular mechanism of EPA-modulated folding, the results showed that EPA-PLs have a chaperone-like function, which explains the 
physiological advantage of LPUFA synthesis in cold environments. Considering that the lack of EPA causes a defect in S. livingstonensis Ac10 cell division, proper function of cell division proteins may require EPA-PLs $[7,18]$. Further studies should address whether the chaperone-like function of LPUFAs generally contributes to efficient membrane insertion, folding, and physiological modulation of membrane proteins in various organisms.

Because the folding efficiency and conformational change of Omp74 increased depending on the presence of EPA, this protein is a useful model to understand the physiological function of acyl chains in membrane phospholipids. Synthetic phospholipids with diverse acyl-group chain length and unsaturation might help to elucidate the structure-function relationship of LPUFAs during folding of membrane proteins. 


\section{Acknowledgments}

This work was supported in part by Grants-in-Aid for Scientific Research (B) from JSPS (20360372, 22404021, and 24380047 to T.K.), a Grant-in-Aid for Challenging Exploratory

Research 22658028 (to T.K.), a Grant from the Institute for Fermentation, Osaka (to T.K.), a

Grant from the Japan Foundation for Applied Enzymology (to T.K.), and a Grant for Research for Promoting Technological Seeds 10-041 from JST (to J.K.). 


\section{References}

[1] N.J. Russell, D.S. Nichols, Polyunsaturated fatty acids in marine bacteria--a dogma rewritten, Microbiology 145 (Pt 4) (1999) 767-779.

[2] C. Kato, Y. Nogi, Correlation between phylogenetic structure and function: examples from deep-sea Shewanella, FEMS Microbiol Ecol 35 (2001) 223-230.

[3] T. Nishida, R. Hori, N. Morita, H. Okuyama, Membrane eicosapentaenoic acid is involved in the hydrophobicity of bacterial cells and affects the entry of hydrophilic and hydrophobic compounds, FEMS Microbiol Lett 306 (2010) 91-96.

[4] W. Stillwell, S.R. Wassall, Docosahexaenoic acid: membrane properties of a unique fatty acid, Chem Phys Lipids 126 (2003) 1-27.

[5] M.J. Bruno, R.E. Koeppe, 2nd, O.S. Andersen, Docosahexaenoic acid alters bilayer elastic properties, Proc Natl Acad Sci U S A 104 (2007) 9638-9643.

[6] D.C. Mitchell, S.L. Niu, B.J. Litman, Enhancement of G protein-coupled signaling by DHA phospholipids, Lipids 38 (2003) 437-443.

[7] J. Kawamoto, T. Kurihara, K. Yamamoto, M. Nagayasu, Y. Tani, H. Mihara, M. Hosokawa, T. Baba, S.B. Sato, N. Esaki, Eicosapentaenoic acid plays a beneficial role in membrane organization and cell division of a cold-adapted bacterium, Shewanella livingstonensis Ac10, J Bacteriol 191 (2009) 632-640.

[8] K. Ichihara, H. Iwasaki, K. Ueda, R. Takizawa, H. Naito, M. Tomosugi, Synthesis of phosphatidylcholine: an improved method without using the cadmium chloride complex of sn-glycero-3-phosphocholine, Chem Phys Lipids 137 (2005) 94-99.

[9] E. Sugawara, H. Nikaido, Pore-forming activity of OmpA protein of Escherichia coli, 
J Biol Chem 267 (1992) 2507-2511.

[10] L.K. Tamm, H. Hong, B. Liang, Folding and assembly of beta-barrel membrane proteins, Biochim Biophys Acta 1666 (2004) 250-263.

[11] S. D'Amico, T. Collins, J.C. Marx, G. Feller, C. Gerday, Psychrophilic microorganisms: challenges for life, EMBO Rep 7 (2006) 385-389.

[12] S. Sato, T. Kurihara, J. Kawamoto, M. Hosokawa, S.B. Sato, N. Esaki, Cold adaptation of eicosapentaenoic acid-less mutant of Shewanella livingstonensis Ac10 involving uptake and remodeling of synthetic phospholipids containing various polyunsaturated fatty acids, Extremophiles 12 (2008) 753-761.

[13] H. Okuyama, Y. Orikasa, T. Nishida, Significance of antioxidative functions of eicosapentaenoic and docosahexaenoic acids in marine microorganisms, Appl Environ Microbiol 74 (2008) 570-574.

[14] N.A. Rodionova, S.A. Tatulian, T. Surrey, F. Jahnig, L.K. Tamm, Characterization of two membrane-bound forms of OmpA, Biochemistry 34 (1995) 1921-1929.

[15] E. Sugawara, H. Nikaido, OmpA protein of Escherichia coli outer membrane occurs in open and closed channel forms, J Biol Chem 269 (1994) 17981-17987.

[16] P.J. Booth, P. Curnow, Membrane proteins shape up: understanding in vitro folding, Curr Opin Struct Biol 16 (2006) 480-488.

[17] S.E. Feller, Acyl chain conformations in phospholipid bilayers: a comparative study of docosahexaenoic acid and saturated fatty acids, Chem Phys Lipids 153 (2008) 76-80.

[18] S. Sato, J. Kawamoto, S.B. Sato, B. Watanabe, J. Hiratake, N. Esaki, T. Kurihara, Occurrence of bacterial membrane microdomain at the cell division site enriched in 
phospholipids with polyunsaturated hydrocarbon chain, J Biol Chem (2012). 


\section{Figure legends}

Figure 1. EPA deficiency in S. livingstonensis Ac10 affects the in vivo folding of a cold-inducible protein, $O \mathrm{mp} 74$

The parent strain (Ac10) and the EPA-less mutant $(\triangle \mathrm{EPA})$ were grown at $4{ }^{\circ} \mathrm{C}$ to the late-log phase, and the membrane proteins were extracted. The crude membrane proteins were heated with SDS sample buffer (Takara Bio, Japan) at $100^{\circ} \mathrm{C}$ for $5 \mathrm{~min}$ (boiled) to obtain the unfolded Omp74. Boiled and unboiled samples were applied to SDS-PAGE. Omp74 was detected with anti-Omp74 serum. "F1" and "F2" indicate Omp74 in 2 different folded forms; "U" indicates unfolded protein. A degraded Omp74 product is marked with an asterisk.

\section{Figure 2. Folding kinetics of Omp74}

Omp74 dissolved in $8 \mathrm{M}$ urea was folded in liposomes of DPPE/DPPG with or without 2.5 mol\% PEPE and $2.5 \mathrm{~mol} \%$ PEPG at $18^{\circ} \mathrm{C}(\mathrm{A})$ and $4^{\circ} \mathrm{C}(\mathrm{B})$. Aliquots were removed at specific time intervals as indicated and subjected to SDS-PAGE analysis without boiling. The folded fraction of Omp74 was quantified by densitometry with Image $\mathrm{J}$ software and plotted as a function of time (right panels). Samples with and without EPA-PLs are represented by closed or open symbols, respectively. The lipid:protein molar ratio was 500:1. The error bars indicate the standard deviation from 3 independent experiments.

\section{Figure 3. EPA-PLs facilitate Omp74 secondary structure formation}

(A) CD spectra of Omp74 reconstituted with liposomes with and without EPA-PLs. Unfolded Omp74 was incubated with liposomes composed of DPPE/DPPG with (black) or 
without (gray) $2.5 \mathrm{~mol} \%$ PEPE and $2.5 \mathrm{~mol} \%$ PEPG for 7 days at $18^{\circ} \mathrm{C}$ to ensure reconstitution, and the samples were analyzed by CD spectroscopy. The spectrum of Omp74 folded in buffer lacking liposomes is represented by a dashed line. (B) The kinetics of secondary structure formation of Omp 74 at $4^{\circ} \mathrm{C}$. The changes in $\mathrm{CD}$ signal at $215 \mathrm{~nm}$ characteristic of $\beta$-sheet structure were monitored. Omp 74 reconstituted with or without EPA is represented by a black or gray line, respectively. The dotted line indicates the change in $\beta$-sheet CD signal of Omp74 folded in buffer lacking liposomes. The lipid:protein molar ratio was 125:1. The arrowhead indicates the start point of $\beta$-sheet structural rearrangement. Reproducibility of CD measurements was confirmed by 3 independent experiments. 


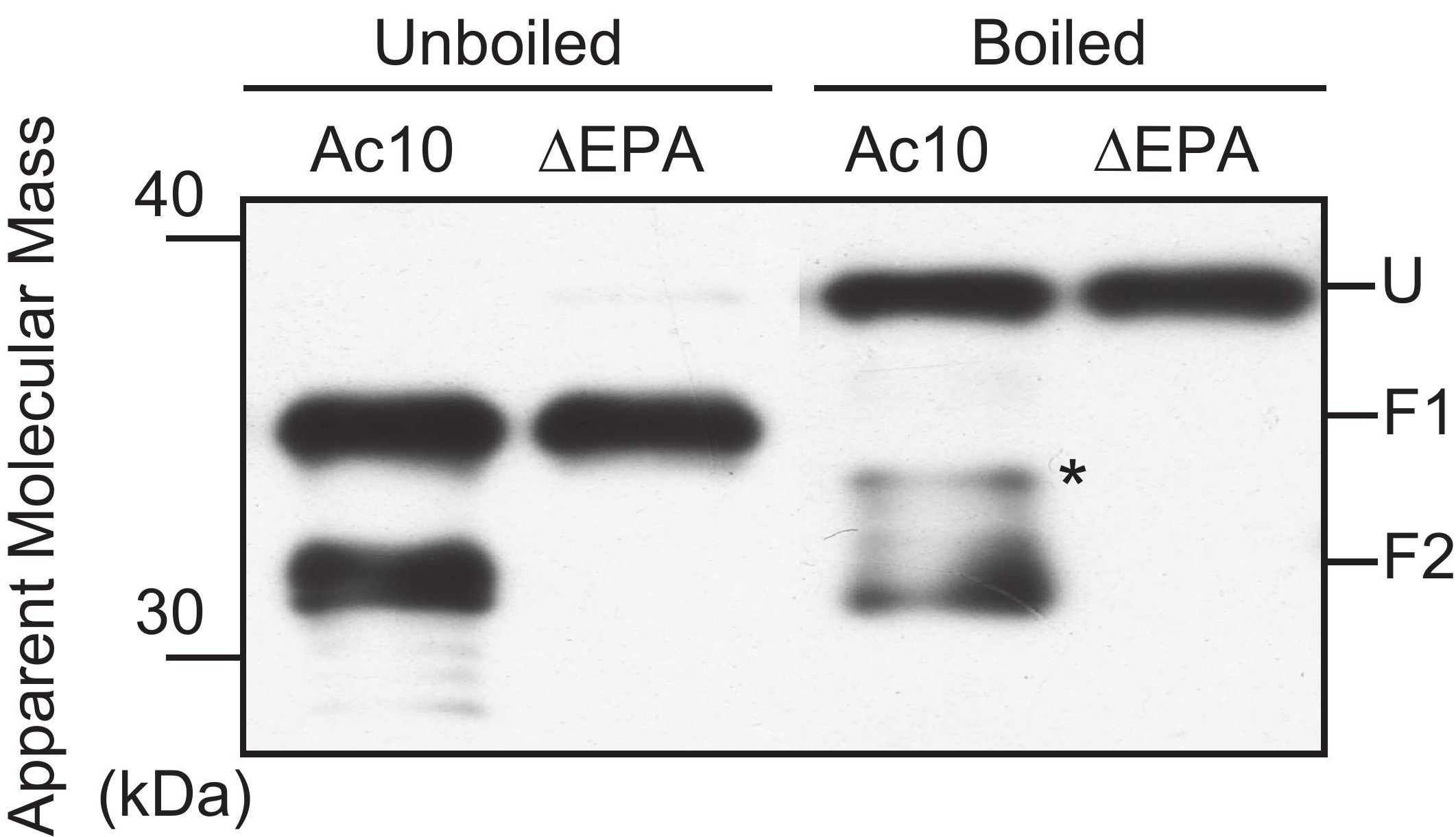


A
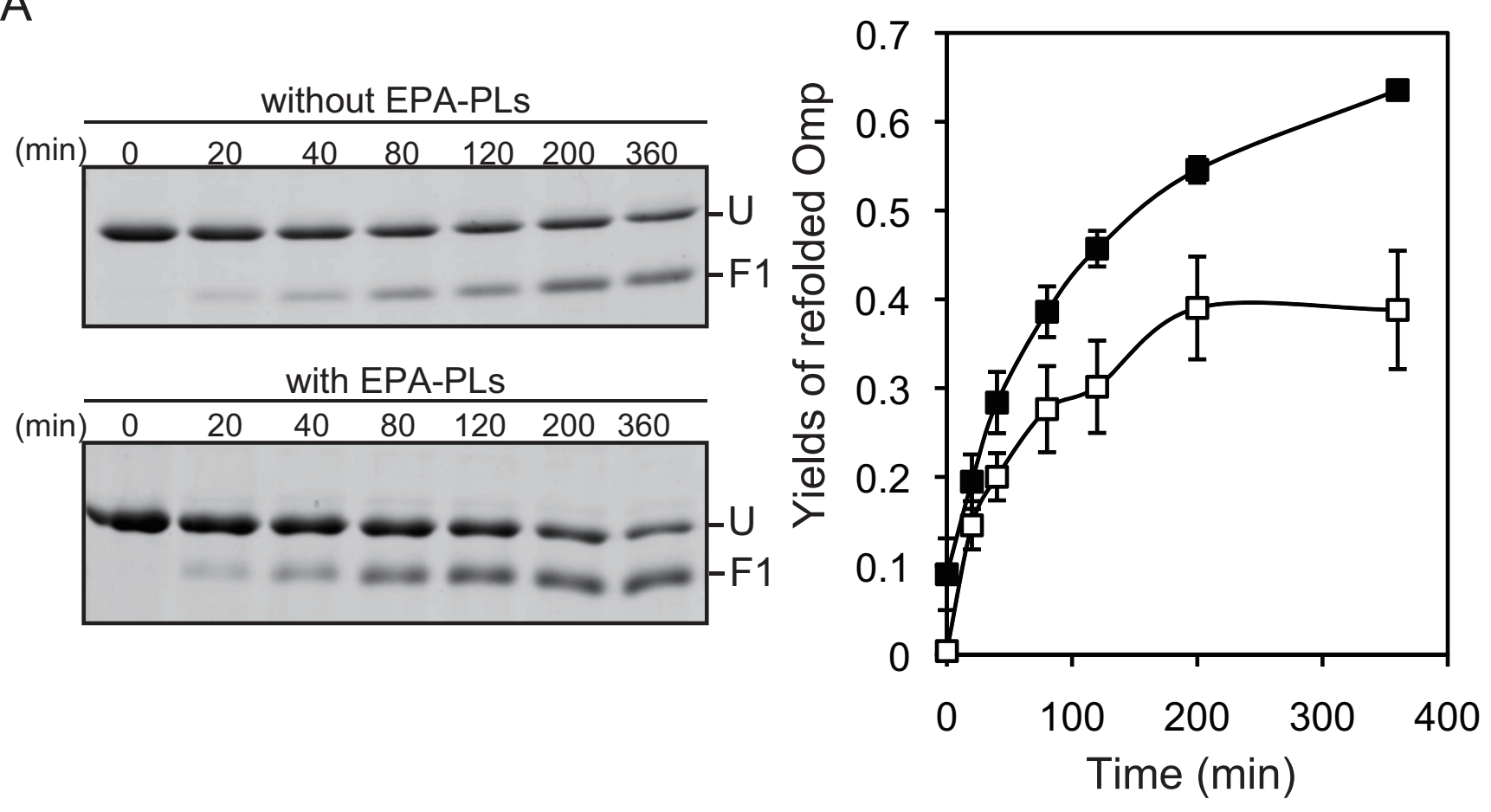

B

with EPA-PLs

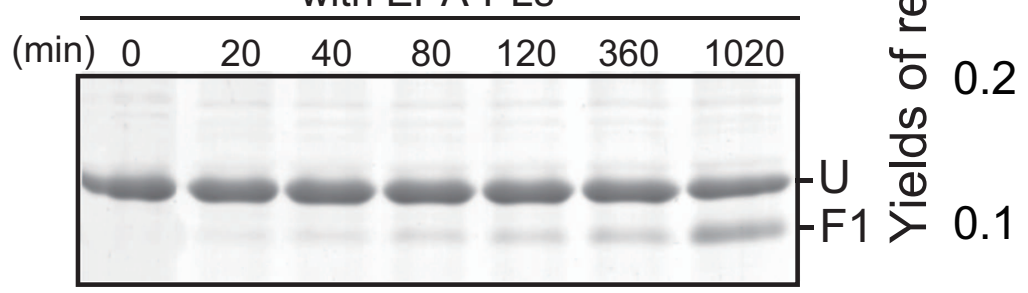

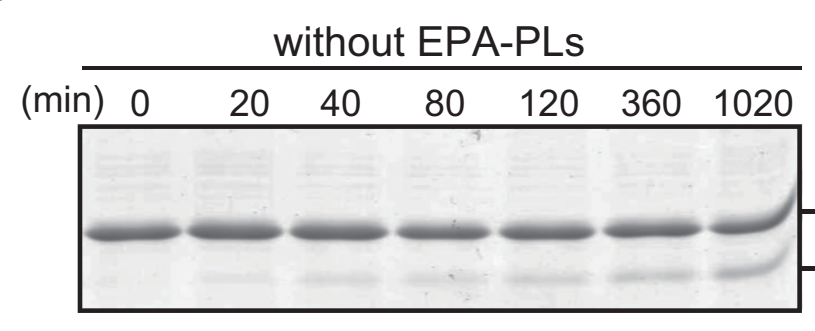

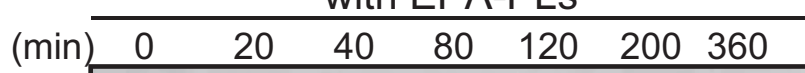

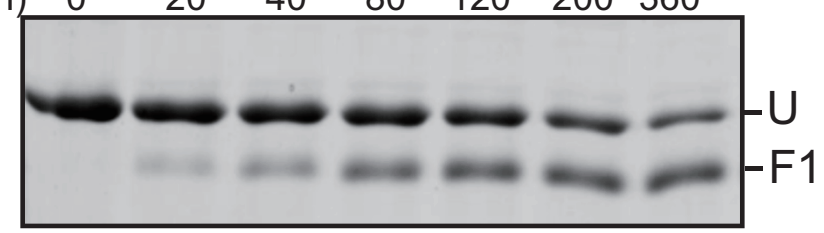

with EPA-PLs

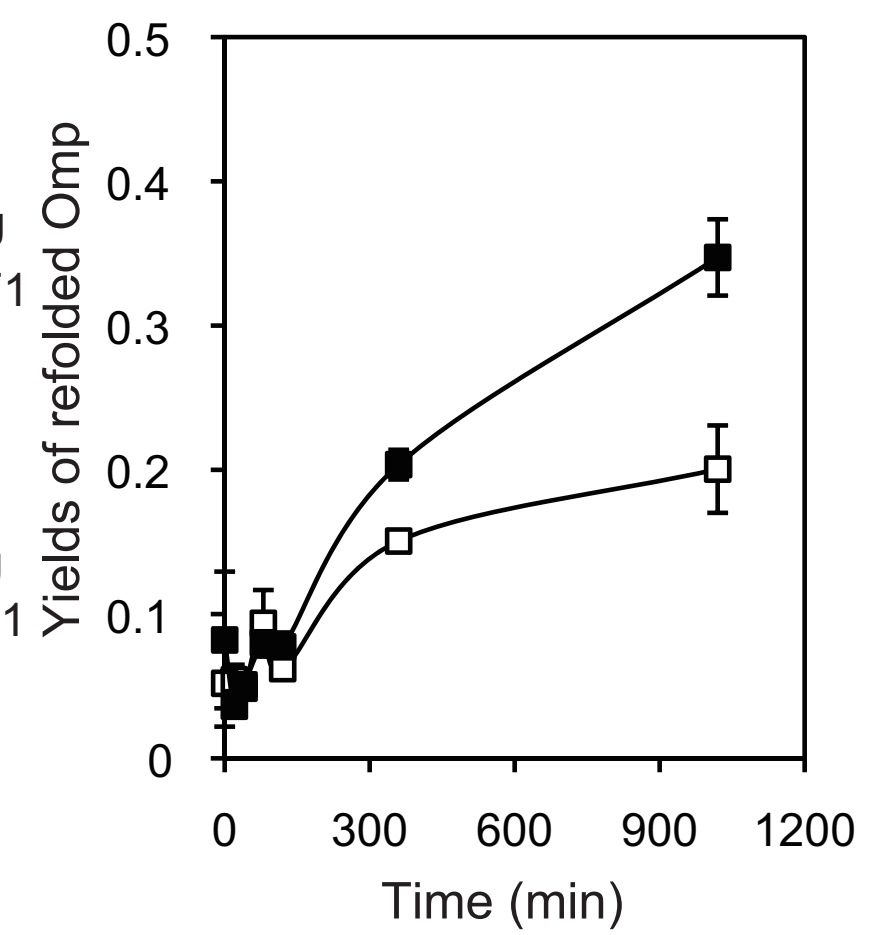


A

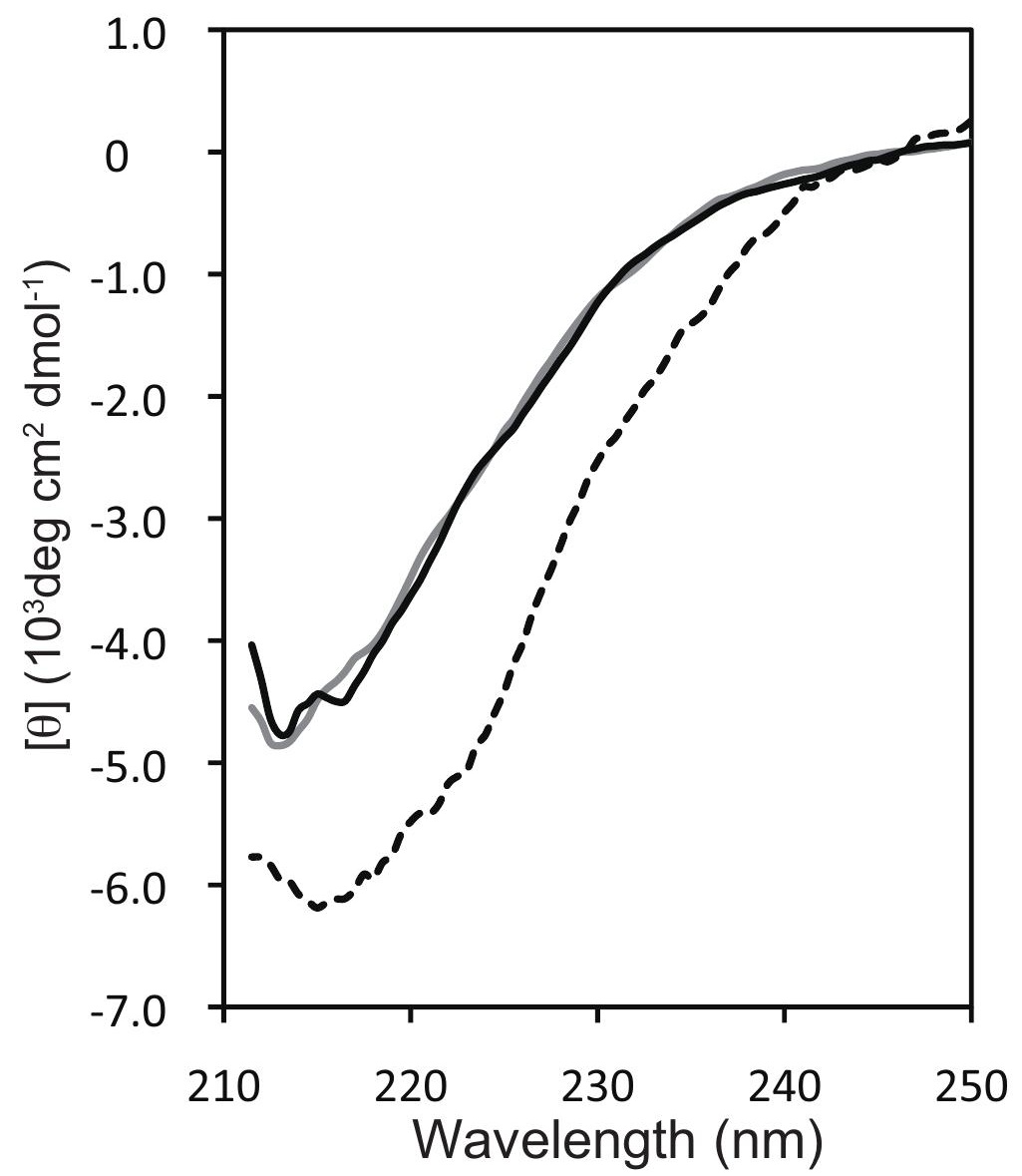

B

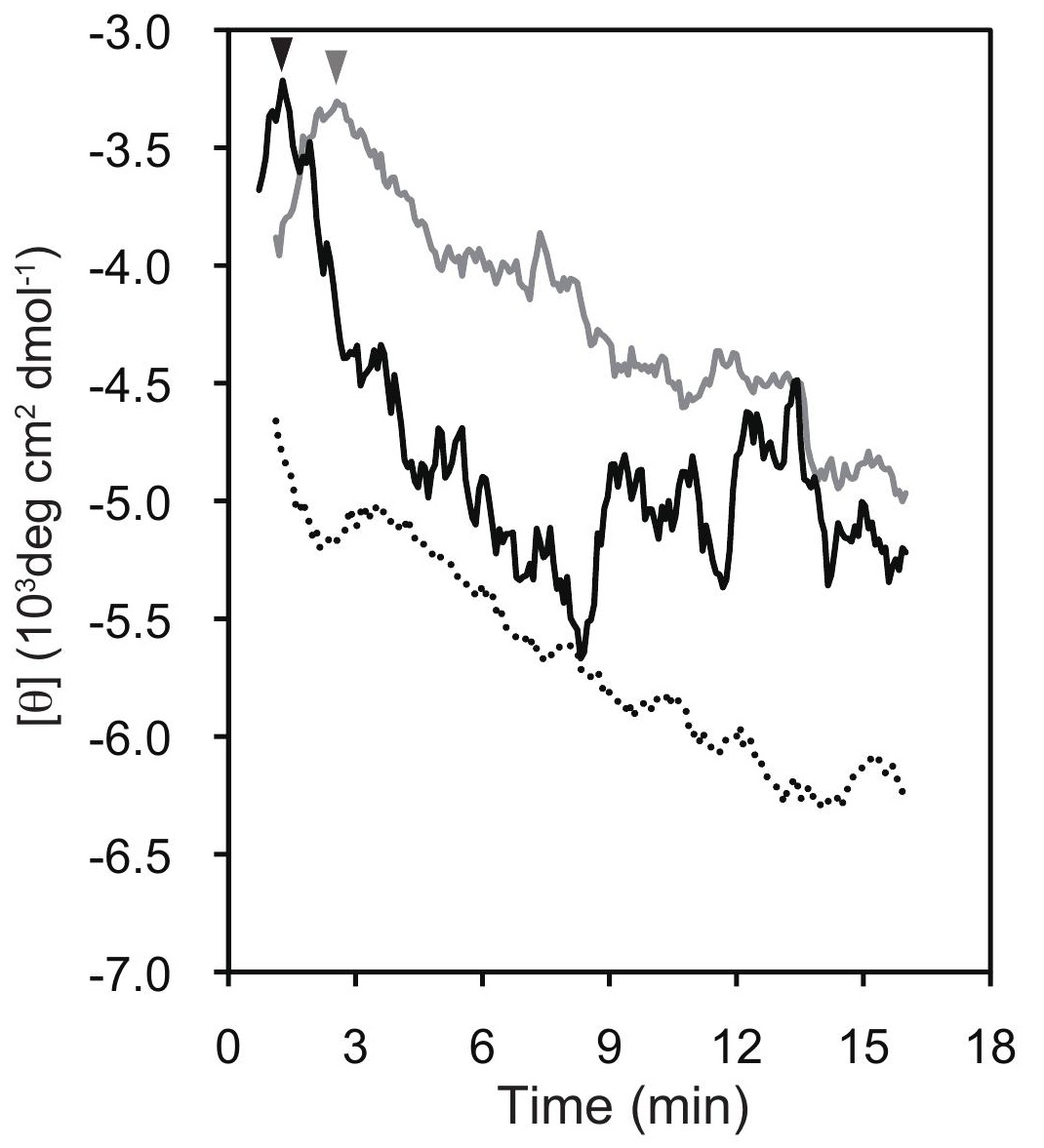




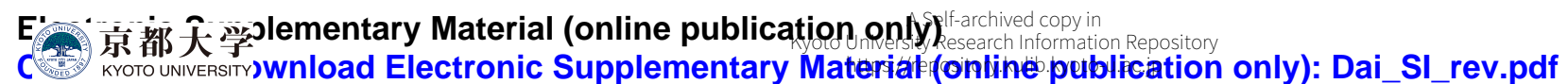

